\title{
Effect of passive immunotherapy on murine gut- derived sepsis caused by Pseudomonas aeruginosa
}

\author{
TETSUYA MATSUMOTO, NOBUHIKO FURUYA, KAZUHIRO TATEDA, SHUICHI MIYAZAKI, AKIRA \\ OHNO, YOSHIKAZU ISHII, YOICHI HIRAKATA* and KEIZO YAMAGUCHI
}

Department of Microbiology, Toho University School of Medicine, 5-21-16 Omori-Nishi, Ota-ku, Tokyo 1438540 and * Department of Laboratory Medicine, Nagasaki University School of Medicine, Sakamoto, Nagasaki, Japan

\begin{abstract}
The effect of passive immunotherapy with antisera against heat-killed Pseudomonas aeruginosa and three of its exo-enzymes (elastase, alkaline protease and exotoxin $A$ ) in gut-derived $\boldsymbol{P}$. aeruginosa sepsis was evaluated. Mice were given a suspension of $\boldsymbol{P}$. aeruginosa strain D4 in their drinking water, together with ampicillin $(200 \mathrm{mg} / \mathrm{kg})$ to disrupt the normal bacterial flora. Cyclophosphamide was then administered to induce translocation of $P$. aeruginosa that had colonised the gastrointestinal tract so that gutderived septicaemia was produced. In this model, intraperitoneal administration of antiserum against heat-killed bacteria, $100 \mu \mathrm{l} /$ mouse, twice a day for 3 consecutive days significantly increased the survival rate over that of mice treated with normal rabbit serum. Antiserum against elastase, alkaline protease, or a combination of these two antisera, failed to provide significant protection. In contrast, antiserum against exotoxin A significantly increased the survival rate over that of mice treated with normal rabbit serum. These results indicate that passive immunisation with antiserum against heatkilled bacteria and exotoxin $A$, but not with antiserum against either elastase or alkaline protease, protects mice against gut-derived sepsis caused by $P$ aeruginosa.
\end{abstract}

\section{Introduction}

Pseudomonas aeruginosa is an important opportunist pathogen that causes severe infections such as septicaemia in immunocompromised patients. Although antibiotics are thought to be the most effective form of therapy against infections caused by this microorganism, they are frequently ineffective due to its innate resistance to various antimicrobial agents. Therefore, effective immunotherapy may potentially represent a useful alternative therapy administered either alone or in combination with antibiotics.

Previous studies have shown that neutrophils [1], complement [2] and immunoglobulins [3] play important roles in host defence against $P$. aeruginosa infection. However, infection with $P$. aeruginosa is frequently identified in immunocompromised patients with neutropenia induced by antineoplastic chemotherapy [4]. Because normal neutrophil function is compromised in patients with neutropenia, humoral immune responses may play a more important role in the recovery of such patients from $P$. aeruginosa

Received 4 Nov. 1998; accepted 28 Nov. 1998.

Corresponding author: Dr T. Matsumoto. infection. Vaccination with microbial antigens may be the most effective method for the induction of protective humoral immune responses [5].

The protective efficacy of immunisation with heatkilled $P$. aeruginosa has been reported previously and such immunisation has been found to provide complete protection of laboratory animals against fulminant sepsis [6]. Studies with vaccines prepared from $P$. aeruginosa alkaline protease, elastase and exotoxin A toxoids showed that a combination of alkaline protease and exotoxin A toxoids represents a potential candidate for vaccination against $P$. aeruginosa sepsis [7]. Although these studies established the efficacy of immunotherapy to develop antibodies in $P$. aeruginosa sepsis, vaccination of immunocompromised patients is frequently unsuccessful because of immunodeficiency [8]. Therefore, passive immunisation may be a more practical method of providing immunotherapy to protect individuals against $P$. aeruginosa infection.

These considerations led to the investigation of the effect of antiserum against heat-killed $P$. aeruginosa and exo-enzymes (elastase, alkaline protease and exotoxin A) on murine gut-derived $P$. aeruginosa 
sepsis associated with neutropenia induced by antineoplastic chemotherapy.

\section{Materials and methods}

\section{Bacterial strain}

P. aeruginosa D4 isolated from the blood of a neutropenic mouse with bacteraemia [9] was used in the present study. The strain was maintained at $-80^{\circ} \mathrm{C}$ in Mueller-Hinton Broth (Difco) containing glycerol $15 \%$.

\section{Preparation of antiserum against heat-killed $P$. aeruginosa and exo-enzymes}

P. aeruginosa grown on Trypticase Soy Agar (BBL) at $37^{\circ} \mathrm{C}$ for $18 \mathrm{~h}$ was suspended in sterile saline to a concentration of $10^{10} \mathrm{cfu} / \mathrm{ml}$. Heat-killed bacteria were prepared by heating the bacterial suspension at $60^{\circ} \mathrm{C}$ for $1 \mathrm{~h}$. The protein concentration was determined with a Protein Assay (BioRad Laboratories, Hercules, CA, USA). For the preparation of rabbit antiserum against heat-killed bacteria, the rabbit was immunised twice at 14-day intervals by intravenous (i.v.) injection of heatkilled bacteria at a protein concentration of $100 \mu \mathrm{g} /$ dose.

Purified exotoxin A was purchased from List Biological Laboratories (Campbell, CA, USA). Purified elastase and purified alkaline protease were purchased from Nagase and Co. Ltd. (Tokyo, Japan). Rabbits were immunised twice at 14-day intervals by i.v. injection of each of these exo-enzymes at a protein concentration of $100 \mu \mathrm{g} / \mathrm{dose}$; thereafter rabbit antisera against these exo-enzymes were prepared.

\section{Animals}

Inbred, specific pathogen-free male ddY mice (Japan Shizuoka Laboratory Centre, Shizuoka, Japan) weighing 20-24 $\mathrm{g}$ were used in the experiments. The animals were housed in sterile cages and received sterile distilled water, except when $P$. aeruginosa was being administered orally. All experimental protocols were approved by the Institutional Animal Care and Use Committee of Toho University School of Medicine.

\section{Survival of mice with gut-derived P. aeruginosa sepsis}

Gut-derived $P$. aeruginosa sepsis was produced as described previously in this laboratory [10-12]. Briefly, bacteria were grown on Trypticase Soy Agar (BBL) at $37^{\circ} \mathrm{C}$ for $18 \mathrm{~h}$, suspended in sterile saline $0.45 \%$, and adjusted to a concentration of $10^{7} \mathrm{cfu} / \mathrm{ml}$. The bacterial suspension was added to the drinking water on days 13. To facilitate in-vivo colonisation of the $P$. aeruginosa strain $\mathrm{D} 4$, that is insensitive to ampicillin, ampicillin $200 \mathrm{mg} / \mathrm{kg} /$ day was injected intraperiton- cally (i.p.) on days $1-3$ to disrupt the normal intestinal flora. Mice were then treated with cyclophosphamide $150-200 \mathrm{mg} / \mathrm{kg}$ by i.p. injection on days 5 and 8 to produce a state of neutropenia. Each experiment was repeated at least twice. Survival was recorded every $24 \mathrm{~h}$ until 7 days after the second administration of cyclophosphamide.

The effect of each antiserum was investigated by i.p. administration; each antiserum was administered twice daily at a dose of $100 \mu \mathrm{l} /$ mouse for 3 days, treatment beginning after the second cyclophosphamide dose. Control mice received identical amounts of normal rabbit serum.

\section{Statistical analysis}

Differences in survival rates among the groups were evaluated by the $\chi^{2}$ test. A p value $<0.05$ denoted a statistically significant difference.

\section{Results}

Effect of antiserum against heat-killed $P$. aeruginosa on the survival of mice after gutderived sepsis

The protective effects of antisera against heat-killed $P$. aeruginosa in mice with gut-derived $P$. aeruginosa sepsis were first evaluated. As shown in Fig. 1, the survival rate of mice treated with the antiserum was significantly higher than that of control mice treated with normal rabbit serum $(\mathrm{p}<0.01)$. This result suggests that administration of antiserum against heatkilled $P$. aeruginosa protects mice against gut-derived sepsis.

\section{Effect of antisera against alkaline protease and elastase of $P$. aeruginosa on the survival of mice after gut-derived sepsis}

The ability of $P$. aeruginosa to produce high levels of exo-enzymes may contribute to the development of fatal septicaemia [13]. Therefore, the protective efficacies of antisera against $P$. aeruginosa alkaline protease and elastase on the survival of mice with gut-derived sepsis were studied. The results demonstrated that administration of antiserum against elastase or alkaline protease alone did not produce a significant protective effect compared with normal rabbit serum (Fig. 2). The effect of using both antisera together was studied in this model; the combined use of the two antisera also failed to provide significant protection.

\section{Effect of antiserum against exotoxin $A$ on the survival of mice with gut-derived $P$. aeruginosa sepsis}

Finally, the effect of antiserum against exotoxin A on the survival of mice with gut-derived sepsis was 


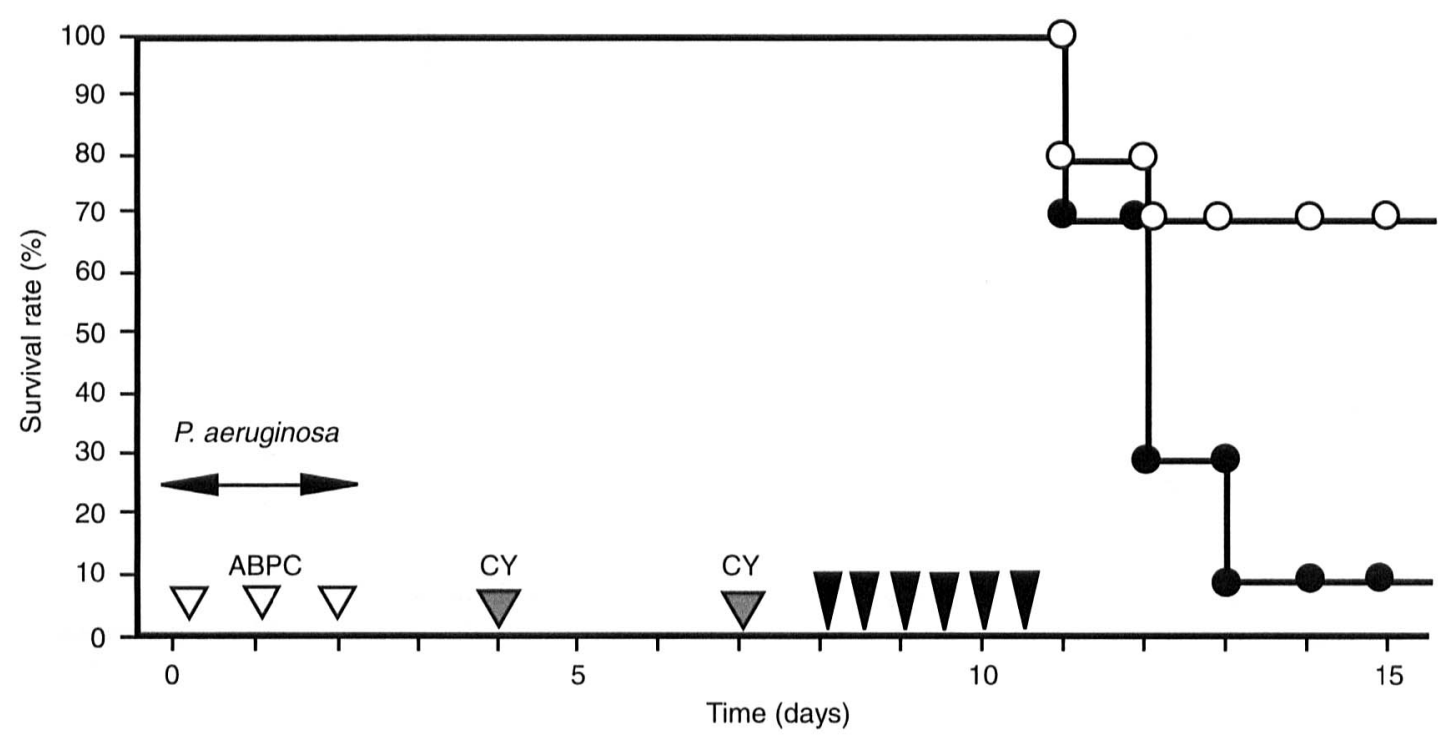

Fig. 1. Effect of antiserum against heat-killed $P$. aeruginosa on the survival of mice with gut-derived septicaemia. Test mice $\left(\mathrm{n}=10,0_{-}\right)$each received $100 \mu \mathrm{l}$ of antiserum against heat-killed $P$. aeruginosa D4 i.p. twice a day for 3 days $(\boldsymbol{\nabla})$, treatment beginning after the second cyclophosphamide dose $(\mathrm{CY})$. Control mice $(\mathrm{n}=10, \bullet-\bullet)$ received identical amounts of normal rabbit serum. ABPC, ampicillin; test versus control, $\mathrm{p}<0.01$.

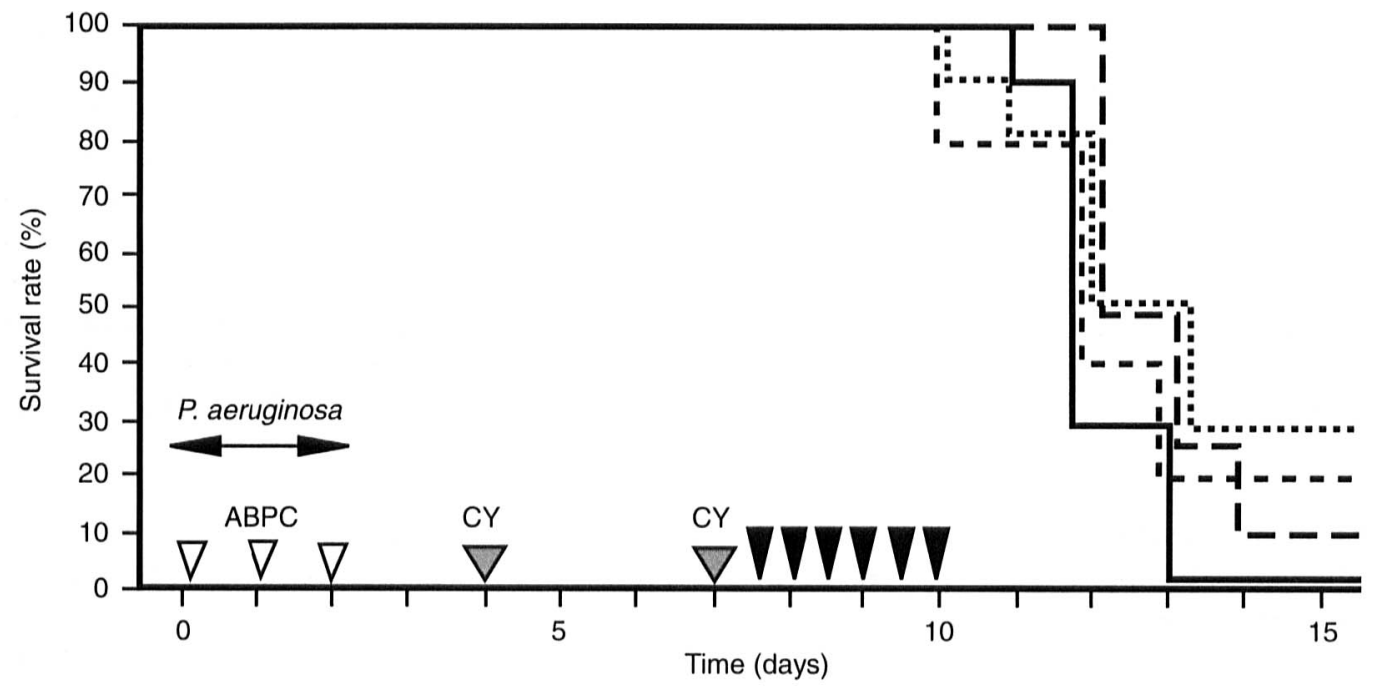

Fig. 2. Effect of antiserum against alkaline protease and elastase of $P$. aeruginosa on the survival of mice with gutderived sepsis. The mice $(\mathrm{n}=10$ in the group) each received $100 \mu \mathrm{l}$ of antiserum against either elastase (.....) or alkaline protease (- - - ) i.p. twice a day for 3 days $(\nabla)$, treatment beginning after the second cyclophosphamide dose (CY). Another group of mice $(\mathrm{n}=10)$ each received $100 \mu 1$ of a combined antiserum against elastase and alkaline protease $(--)$. Control mice $(n=15)$ received identical amounts of normal rabbit serum $(-)$. ABPC, ampicillin.

studied. Fig. 3 shows the survival kinetics of mice inoculated with anti-exotoxin $\mathrm{A}$ antiserum or normal rabbit serum as a control. The results clearly showed a significant improvement of the survival of mice treated with anti-exotoxin A over that of mice treated with normal rabbit serum.

\section{Discussion}

Previous studies have demonstrated that gut bacteria can cross the gastrointestinal mucosal barrier and spread systemically, a process termed bacterial translocation $[14,15]$. Tani et al. [16] reported two patients who developed septic shock that was probably caused by bacterial translocation. Other clinical studies employing faecal surveillance cultures from neutropenic leukaemic patients have shown that $>80 \%$ of patients with bacteraemia caused by $P$. aeruginosa were intestinal carriers of the same strain, suggesting that the gastrointestinal tract may be the primary reservoir of opportunist bacteria [17]. Therefore, translocation of micro-organisms from the gastrointestinal tract may play a role in the pathogenesis of septic complications, especially in immunocompromised patients, and $P$. aeruginosa may be the major pathogen in this type of infection.

Berg et al. [18] reported that gram-negative enteric bacilli translocated systemically in mice treated with 


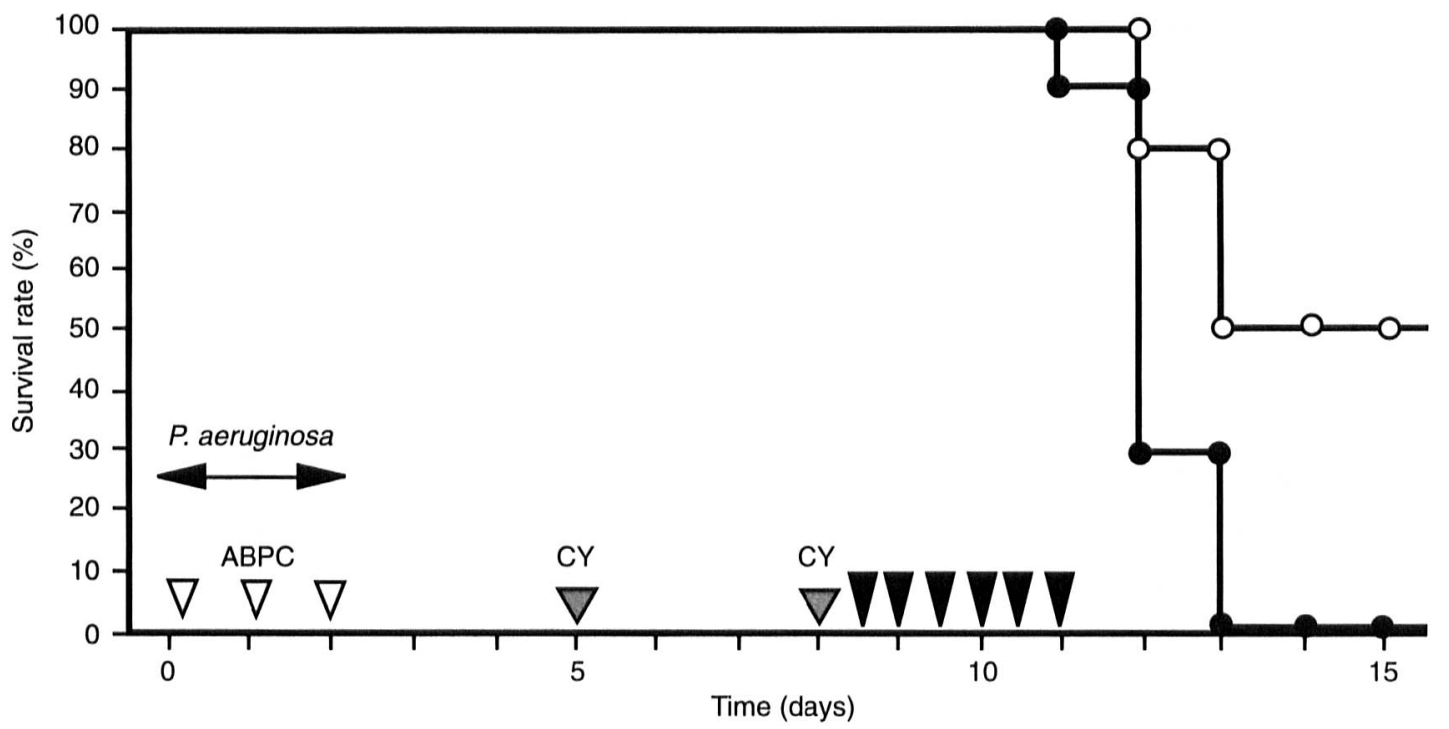

Fig. 3. Effect of antiserum against exotoxin $\mathrm{A}$ on the survival of mice with gut-derived $P$ aeruginosa sepsis. Test mice $(\mathrm{n}=10,0-0)$ each received $100 \mu \mathrm{l}$ of antiserum against exotoxin A i.p. twice a day for 3 days $(\nabla)$, treatment beginning after the second cyclophosphamide dose (CY). Control mice $(n=10, \bullet-\bullet)$ received identical amounts of normal rabbit serum. ABPC, ampicillin; test versus control, $\mathrm{p}<0.05$.

antibiotics combined with an immunosuppressive drug, such as penicillin $G$ and cyclophosphamide. In the present study, gut-derived $P$. aeruginosa sepsis was induced by administering ampicillin and cyclophosphamide to specific pathogen-free mice fed this organism. In this model, $P$. aeruginosa colonises the intestinal tract and invades body tissues after induction of immunosuppression or disruption of the intestinal mucosal barrier by administration of cyclophosphamide. Once the bacteria pass through the trap of Kupffer cells in the liver, systemic bacteraemia develops, followed by death in the majority of animals. This model resembles the septic infection caused in man by pathogens derived from the intestinal tract, especially in immunocompromised patients [19].

The virulence of $P$ aeruginosa is multifactorial and depends on several extracellular enzymes and other substances [20]. As experimental data suggest that lipopolysaccharide (LPS) is an important virulence factor in $P$. aeruginosa infection, most studies have focused on the protective activities of anti-LPS antibody or polysaccharide vaccines $[5,21-24]$. The protective effects of immunisation with heat-killed $P$. aeruginosa have been shown recently in this laboratory and the data suggested that the main protective antibodies induced by vaccination might be those specific to LPS [6]. On the basis of these early results and the present findings, the hypothesis seems likely that the protective activity of antiserum against heatkilled $P$. aeruginosa was mainly induced by antibodies against LPS included in the antiserum.

Although immunotherapy with antibodies against LPS may be the most protective in $P$. aeruginosa infection, the presence of a wide variety of LPS serotypes of $P$. aeruginosa makes it difficult to produce protective antibodies that have a wide spectrum of efficacy against $P$. aeruginosa [21-23, 25-27]. On the other hand, there may be common antigenicities in the exoenzymes (elastase, alkaline protease and exotoxin A) of $P$. aeruginosa, which have also been reported to be important virulence factors in $P$. aeruginosa infection [28-30]. These findings suggest that antibodies against these exo-enzymes might be useful for immunotherapy and protection against a wide range of $P$. aeruginosa strains.

Elastase interferes with the host immune system by cleaving $\operatorname{IgG}$ and $\operatorname{IgA}[31,32]$, by inhibiting the activity of various cytokines [33] and by interfering with the function of neutrophils [34], $T$ cells [35] and natural killer cells [36]. Immunisation with elastase toxoid is effective in certain experimental models of $P$. aeruginosa infection [37-39]. However, passively transferred IgG of anti-elastase serum showed no protective effect against $P$. aeruginosa in a murine burn wound sepsis model [23] or in an experimental leukopenic mouse model [40]. The results of the present study also failed to show any protective effect of antiserum against elastase; therefore, elastase is probably a less important virulence factor in gutderived sepsis.

Alkaline protease is reported to cleave IgG [31], to degrade interferon- $\gamma$ [41] and to inhibit neutrophil function [34]. The effectiveness of immunisation with alkaline protease toxoid has been described in haemorrhagic pneumonia in mink [37] and burns in mice [39]. These studies confirmed the importance of alkaline protease as a virulence factor and showed the effectiveness of immunisation with alkaline protease in the prevention of infection with $P$. aeruginosa. 
However, the present study did not demonstrate a protective effect for antiserum against alkaline protease in murine gut-derived sepsis; and a combination treatment consisting of antisera against elastase and alkaline protease also failed to provide significant protection. In this regard, Wretlind et al. [42] argued that although elastase and alkaline protease might play a part in localised $P$. aeruginosa infections, these enzymes are probably less important after septicaemia is established. Thus, elastase and alkaline protease may not contribute significantly to the pathogenicity of septicaemia in this mouse model.

Exotoxin $\mathrm{A}$ is believed to be the most toxic virulence factor produced by $P$. aeruginosa [43] and its cytotoxic activity extends to a wide variety of mammalian cells [44]. The importance of exotoxin A as a principal lethal factor has been demonstrated in a few studies of experimental $P$. aeruginosa infection $[45,46]$. In this laboratory, infection of mice with an exotoxin-deficient mutant of $P$. aeruginosa (PA0-PR1) was associated with a significantly lower mortality than that associated with the parent strain [28]. This present study has also demonstrated the protective action of antiserum against exotoxin A. Taken together, data from these experiments support the role of exotoxin $\mathrm{A}$ as an important factor in the pathogenesis of gut-derived sepsis.

Previous studies have indicated that the importance of each of the above exo-enzymes as a virulence factor may vary from one model to another $[1,13,47]$. Therefore, the importance of these exo-enzymes in the pathogenesis of $P$. aeruginosa infections may depend on the type of infection. Furthermore, it is concluded that these exo-enzymes are not necessarily equally significant in $P$. aeruginosa infection and that exotoxin A may contribute to the development of gut-derived sepsis caused by $P$. aeruginosa.

The authors are grateful to Dr Shogo Kuwahara for his useful advice and Ms Yasuko Kaneko for expert technical assistance. We also thank Dr F. G. Issa (Word-Medex, Sydney, Australia) for the careful reading and editing of the manuscript. This study was supported by a research grant provided by the Japan Health Sciences Foundation, Tokyo, Japan.

\section{References}

1. Tamura Y, Suzuki S, Sawada T. Role of elastase as a virulence factor in experimental Pseudomonas aeruginosa infection in mice. Microb Pathog 1992; 12: 237-244.

2. Alpert SE, Penningtion JE, Colten HR. Synthesis of complement by guinea pig bronchoalveolar macrophages. Effect of acute and chronic infection with Pseudomonas aeruginosa. Am Rev Respir Dis 1984; 129: 66-71.

3. Richardson JD, DeCamp MM, Garrison RN, Fry DE. Pulmonary infection complicating intra-abdominal sepsis Clinical and experimental observations. Ann Surg 1982; 195: $732-738$.

4. Dick JD, Shull V, Karp JE, Valentine J. Bacterial and host factors affecting Pseudomonas aeruginosa colonization versus bacteremia in granulocytopenic patients. Eur $J$ Cancer Clin Oncol 1988; 24 Suppl 1: S47-S54.
5. Cryz SJ, Fürer E, Germanier R. Protection against fatal Pseudomonas aeruginosa burn wound sepsis by immunization with lipopolysaccharide and high-molecular-weight polysaccharide. Infect Immun 1984; 43: 795-799.

6. Matsumoto $\mathrm{T}$, Tateda $\mathrm{K}$, Miyazaki $\mathrm{S}$ et al. Effect of immunisation with Pseudomonas aeruginosa on gut-derived sepsis in mice. J Med Microbiol 1998; 47: 295-301.

7. Matsumoto T, Tateda K, Furuya N et al. Efficacies of alkaline protease, elastase and exotoxin A toxoid vaccines against gutderived Pseudomonas aeruginosa sepsis in mice. $J$ Med Microbiol 1998; 47: 303-308.

8. Gottlieb DJ, Cryz SJ, Furer E et al. Immunity against Pseudomonas aeruginosa adoptively transferred to bone marrow transplant recipients. Blood 1990; 76: 2470-2475.

9. Hirakata Y, Tomono K, Tateda K et al. Role of bacterial association with Kupffer cells in occurrence of endogenous systemic bacteremia. Infect Immun 1991; 59: 289-294.

10. Matsumoto T, Tateda $\mathrm{K}$, Miyazaki $\mathrm{S}$ et al. Immunomodulating effect of fosfomycin on gut-derived sepsis caused by Pseudomonas aeruginosa in mice. Antimicrob Agents Chemother 1997; 41: 308-313.

11. Matsumoto T, Tateda K, Miyazaki S et al. Adverse effects of tumour necrosis factor in cyclophosphamide-treated mice subjected to gut-derived Pseudomonas aeruginosa sepsis. Cytokine 1997; 9: 763-769.

12. Matsumoto $\mathrm{T}$, Tateda $\mathrm{K}$, Miyazaki $\mathrm{S}$ et al. Paradoxical synergistic effects of tumor necrosis factor and interleukin-1 on murine gut-derived Pseudomonas aeruginosa sepsis. Cytokine 1998 (in press).

13. Furuya N, Hirakata Y, Tomono $\mathrm{K}$ et al. Mortality rates amongst mice with endogenous septicaemia caused by Pseudomonas aeruginosa isolates from various clinical sources. J Med Microbiol 1993; 39: 141-146.

14. Berg RD, Garlington AW. Translocation of Escherichia coli from the gastrointestinal tract to the mesenteric lymph nodes in gnotobiotic mice receiving Escherichia coli vaccines before colonization. Infect Immun 1980; 30: 894-898.

15. Deitch EA, Winterton J, Berg R. Thermal injury promotes bacterial translocation from the gastrointestinal tract in mice with impaired T-cell-mediated immunity. Arch Surg 1986; 121: 97-101.

16. Tani $\mathrm{T}$, Hanasawa $\mathrm{K}$, Endo $\mathrm{Y}$ et al. Bacterial translocation as a cause of septic shock in humans: a report of two cases. Surg Today 1997; 27: 447-449.

17. Tancrède $\mathrm{CH}$, Andremont $\mathrm{AO}$. Bacterial translocation and gram-negative bacteremia in patients with hematological malignancies. J Infect Dis 1985; 152: 99-103.

18. Berg RD, Wommack E, Deitch EA. Immunosuppression and intestinal bacterial overgrowth synergistically promote bacterial translocation. Arch Surg 1988; 123: 1359-1364.

19. Hirakata Y, Kaku M, Mizukane R et al. Potential effects of erythromycin on host defense systems and virulence of Pseudomonas aeruginosa. Antimicrob Agents Chemother 1992; 36: 1922-1927.

20. Woods DE, Vasil ML. Pathogenesis of Pseudomonas aeruginosa infections. In: Baltch AL, Smith RP (eds) Pseudomonas aeruginosa infections and treatment. New York. Marcel Dekker. 1993: 21-50.

21. Stoll BJ, Pollack M, Young LS, Koles N, Gascon R, Pier GB. Functionally active monoclonal antibody that recognizes an epitope on the $\mathrm{O}$ side chain of Pseudomonas aeruginosa immunotype-1 lipopolysaccharide. Infect Immun 1986; 53: $656-662$.

22. Sawada S, Kawamura T, Masuho Y. Immunoprotective human monoclonal antibodies against five major serotypes of Pseudomonas aeruginosa. J Gen Microbiol 1987; 133: 3581-3590.

23. Cryz SJ, Fürer E, Germanier R. Protection against Pseudomonas aeruginosa infection in a murine burn wound sepsis model by passive transfer of antitoxin $\mathrm{A}$, antielastase, and antilipopolysaccharide. Infect Immun 1983; 39: 1072-1079.

24. Bhattacharjee AK, Opal SM, Palardy JE et al. Affinity-purified Escherichia coli J5 lipopolysaccharide-specific IgG protects neutropenic rats against gram-negative bacterial sepsis. $J$ Infect Dis 1994; 170: 622-629.

25. Terashima M, Uezumi I, Tomio $\mathrm{T}$ et al. A protective human monoclonal antibody directed to the outer core region of Pseudomonas aeruginosa lipopolysaccharide. Infect Immun 1991; 59: 1-6.

26. Yokota S-I, Terashima M, Chiba J, Noguchi H. Variable cross- 
reactivity of Pseudomonas aeruginosa lipopolysaccharide-codespecific monoclonal antibodies and its possible relationship with serrotype. J Gen Microbiol 1992; 138: 289-296.

27. Pennington JE, Small GJ, Lostrom ME, Pier GB. Polyclonal and monoclonal antibody therapy for experimental Pseudomonas aeruginosa pneumonia. Infect Immun 1986; 54: 239-244.

28. Hirakata Y, Furuya N, Tateda K, Kaku M, Yamaguchi K. In vivo production of exotoxin $\mathrm{A}$ and its role in endogenous Pseudomonas aeruginosa septicemia in mice. Infect Immun 1993; 61: 2468-2473.

29. Drake D, Montie TC. Flagella, motility and invasive virulence of Pseudomonas aeruginosa. J Gen Microbiol 1988; 134: 43-52.

30. Goto S. Recent progress in the identification of pathogenic factors of Pseudomonas aeruginosa. J Infect Chemother 1996; 2: $111-116$.

31. Doring G, Dalhoff A, Vogel O, Brunner H, Dröge U, Botzengart K. In vivo activity of proteases of Pseudomonas aeruginosa in a rat model. $J$ Infect Dis 1984; 149: 532-537.

32. Fick RB, Baltimore RS, Squier SU, Reynolds HY. IgG proteolytic activity of Pseudomonas aeruginosa in cystic fibrosis. J Infect Dis 1985; 151: 589-598.

33. Parmely $M$, Gale A, Clabaugh $M$, Horvat $R$, Zhou W-W. Proteolytic inactivation of cytokines by Pseudomonas aeruginosa. Infect Immun 1990; 58: 3009-3014.

34. Kharazmi A, Eriksen HO, Döring G, Goldstein W, Høiby N Effect of Pseudomonas aeruginosa proteases on human leukocyte phagocytosis and bactericidal activity. Acta Pathol Microbiol Immunol Scand - Sect C, Immunol 1986; 94: $175-179$.

35. Theander TG, Kharazmi A, Pedersen BK et al. Inhibition of human lymphocyte proliferation and cleavage of interleukin-2 by Pseudomonas aeruginosa proteases. Infect Immun 1988; 56 1673-1677.

36. Pedersen BK, Kharazmi A, Theander TG, Ødum N, Andersen $\mathrm{V}$, Bendtzen $\mathrm{K}$. Selective modulation of the CD4 molecula complex by Pseudomonas aeruginosa alkaline protease and elastase. Scand J Immunol 1987; 26: 91-94.
37. Homma JY, Abe C, Tanamoto $\mathrm{K}$ et al. Effectiveness of immunization with single and multi-component vaccines prepared from a common antigen (OEP), protease and elastase toxoids of Pseudomonas aeruginosa on protection against hemorrhagic pneumonia in mink due to $P$. aeruginosa. Jpn $J$ Exp Med 1978; 48: 111-133.

38. Gilleland HE, Gilleland LB, Fowler MR. Vaccine efficacies of elastase, exotoxin $\mathrm{A}$, and outer-membrane protein $\mathrm{F}$ in preventing chronic pulmonary infection by Pseudomonas aeruginosa in a rat model. J Med Microbiol 1993; 38: 79-86.

39. Kawaharajo K, Homma JY. Effects of elastase, protease and common antigen (OEP) from Pseudomonas aeruginosa on protection against burns in mice. Jpn $J$ Exp Med 1977; 47: 495-500.

40. Cryz SJ, Fürer E, Germanier R. Passive protection against Pseudomonas aeruginosa infection in an experimental leukopenic mouse nodel. Infect Immun 1983; 40: 659-664.

41. Horvat RT, Parmely MJ. Pseudomonas aeruginosa alkaline protease degrades human gamma interferon and inhibits its bioactivity. Infect Immun 1988; 56: 2925-2932.

42. Wretlind B, Pavlovskis OR. The role of proteases and exotoxin A in the pathogenicity of Pseudomonas aeruginosa infections. Scand J Infect Dis 1981; Suppl 29: 13-19.

43. Liu PV. Extracellular toxins of Pseudomonas aeruginosa. $J$ Infect Dis 1974; 130 Suppl: S94-S99.

44. Misfeldt ML, Legaard PX, Howell SE, Fornella MG, LeGrand $\mathrm{RD}$. Induction of interleukin-1 from murine peritoneal macrophages by Pseudomonas aeruginosa exotoxin A. Infect Immun 1990; 58: 978-982.

45. Galloway DR, Hedstrom RC, Pavlovskis OR. Production and characterization of monoclonal antibodies to exotoxin A from Pseudomonas aeruginosa. Infect Immun 1984; 44: 262-267.

46. Pavlovskis OR, Pollack M, Callahan LT, Iglewski BH. Passive protection by antitoxin in experimental Pseudomonas aeruginosa burn infections. Infect Immun 1977; 18: 596-602.

47. Baker NR. Role of exotoxin A and proteases of Pseudomonas aeruginosa in respiratory tract infections. Can $J$ Microbiol 1982; 28: $248-255$. 